\title{
Case Report \\ T-Cell Lymphoblastic Lymphoma in a Child Presenting as Rapid Thyroid Enlargement
}

\author{
Shintaro Yoshihara, ${ }^{1,2}$ Muneo Nakaya, ${ }^{2}$ and Tomoya Ichikawa ${ }^{1}$ \\ ${ }^{1}$ Department of Otolaryngology-Head and Neck Surgery, Tokyo Metropolitan Children's Medical Center, Fuchu, Tokyo 183-8501, Japan \\ ${ }^{2}$ Department of Otolaryngology-Head and Neck Surgery, Tokyo Metropolitan Tama Medical Center, Fuchu, Tokyo 183-8524, Japan
}

Correspondence should be addressed to Shintaro Yoshihara; yoshiharas.oto@gmail.com

Received 24 May 2014; Revised 17 July 2014; Accepted 18 July 2014; Published 24 July 2014

Academic Editor: Abrão Rapoport

Copyright (C) 2014 Shintaro Yoshihara et al. This is an open access article distributed under the Creative Commons Attribution License, which permits unrestricted use, distribution, and reproduction in any medium, provided the original work is properly cited.

\begin{abstract}
The majority of lymphomas of the head and neck in children present as an enlarged cervical lymph node; however, malignant lymphoma arising from the thyroid gland is extremely rare. We report a case of a 12-year-old child who was admitted to our hospital because of a history of rapidly progressive anterior neck swelling. Histopathological studies revealed this case to be T-cell lymphoblastic lymphoma. We performed chemotherapy and the patient has kept recurrence-free survival for 18 months after the beginning of the treatment. This is the 2nd case of T-cell lymphoblastic lymphoma in the thyroid gland in a child.
\end{abstract}

\section{Introduction}

Non-Hodgkin's lymphoma (NHL) is one of the most common head and neck pediatric malignancies commonly involving cervical lymph node, salivary glands, larynx, sinuses, orbit, and extranodal lymphoid tissue of Waldeyer's ring [1]. Primary thyroid lymphoma (PTL) in children is extremely rare; thus, there have been only 8 English literatures reported [1-8]. Furthermore, this is the 2nd case when limited to the subtype T-cell lymphoblastic lymphoma (T-LBL).

T-LBL accounts for $30 \%$ of all pediatric NHL cases and shows many similarities with T-cell acute lymphoblastic leukemia (T-ALL). The primary site of disease and the degree of bone marrow involvement distinguish these two disease entities clinically. Even the subtle molecular and cytogenic differences indicate that T-LBL and T-ALL do not share an immunophenotypic and oncogenic profile; T-LBL is an aggressive NHL and frequently invades the central nerve system (CNS); therefore, the treatment for T-LBL should include intensified chemotherapy as is the case for treatment of T-ALL $[9,10]$.

Herein we report a case of a 12 -year-old child with TLBL arising from the thyroid gland and describe its process of diagnosis and treatment.

\section{Case Presentation}

A 12-year-old Japanese child was admitted to our hospital because of a 3-day history of rapidly progressive anterior neck swelling (Figure 1). The mass was firm and nontender without pain or redness. Cervical lymphadenopathy was not recognized. His medical history was unremarkable and "B symptoms" were not obvious. There were no abnormalities in laboratory findings including thyroid functionality such as thyroid stimulating hormone (TSH) $1.47 \mu \mathrm{IU} / \mathrm{mL}$, free triiodothyronine (fT3) $4.64 \mathrm{pg} / \mathrm{mL}$ and free thyroxine (fT4) $1.13 \mathrm{ng} / \mathrm{mL}$. Ultrasound examinations showed a large poorly defined tumor consisting of central numerous punctate lesion and peripheral hypoechoic area with increased vascularity. Calcification and cystic lesions were not present. Computerized tomography (CT) scan (Figure 2), magnetic resonance imaging (MRI), and scintigraphy using $201 \mathrm{Tl}-\mathrm{Cl}$ (69 MBq) suggested that the mass was a thyroid cancer in the inferior pole of the left thyroid gland with central necrosis. On the other hand, fine needle aspiration cytology of Papanicolaou stain revealed it to be class IV, suggesting malignant lymphoma (ML).

After discussion with haematologists and the patient's family, we decided to treat the patient with chemotherapy 


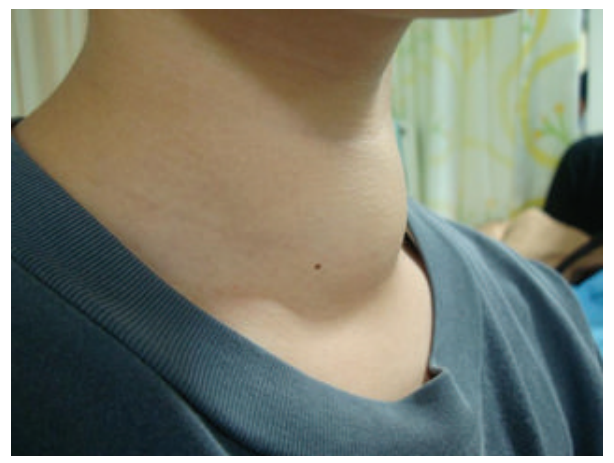

FIGURE 1: Anterior neck swelling without pain or redness.

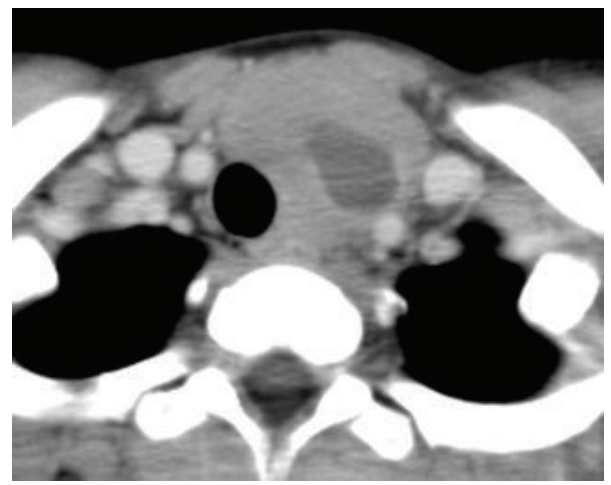

FIgURE 2: Initial axial computerized tomography scan. The thyroid mass in the inferior thyroid gland with a central necrotic area.

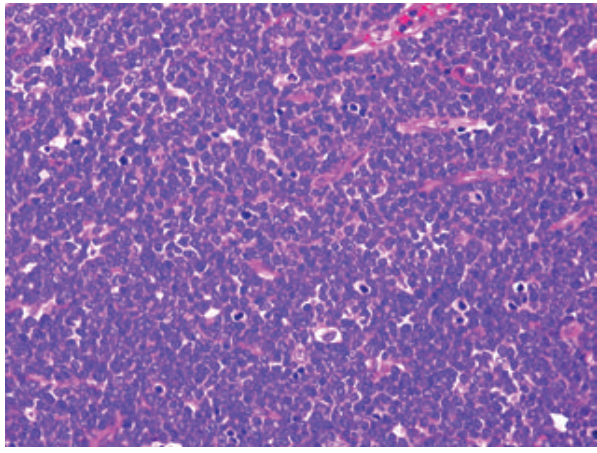

(a)

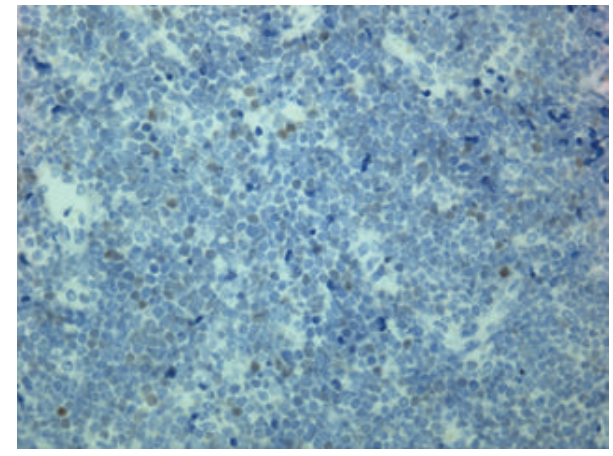

(b)

Figure 3: Histopathological examinations. T-cell lymphoblastic lymphoma. (a) The tumor was composed of medium sized lymphoblast with inconspicuous nucleoli $(\mathrm{H} \& \mathrm{E} ; \times 40)$. (b) The tumor cells were TdT positive.

according to the specific subtype of histopathology and avoid total thyroidectomy to preserve thyroid function. We performed open biopsy under general anesthesia and excised a $1 \mathrm{~cm}^{3}$ specimen. After the surgery, TSH was $0.843 \mu \mathrm{IU} / \mathrm{mL}$, fT3 $4.87 \mathrm{pg} / \mathrm{mL}$, and fT4 $1.14 \mathrm{ng} / \mathrm{mL}$.

Histopathological examinations including immunohistochemistry and flow cytometry showed CD45+, CD2+, $\mathrm{CD} 3+, \mathrm{CD} 4+, \mathrm{CD} 5+, \mathrm{CD} 7+, \mathrm{CD} 8+, \mathrm{CD} 10+$, and Terminal deoxynucleotidyl transferase (TdT)+; thus, the diagnosis was confirmed as T-LBL of the thyroid gland (Figures 3(a) and 3(b)). Additional investigations such as examinations of bone marrow and cerebrospinal fluid (CSF), MRI of the brain, and positron emission tomography (PET)-CT scan showed no evidence of metastasis; however, a CT scan indicated the possibility of swelling of the right tonsil. Hence we classified the present case as Murphy's classification stage II [11].

The patient has been treated with chemotherapy in accordance with the protocol of Japan Pediatric Leukemia/Lymphoma Study Group (JPLSG). The protocol consists of prednisolone, vincristine, cyclophosphamide, daunorubicin, L-asparaginase, hydrocortisone, cytarabine, 6-mercaputopurine, and methotrexate. The thyroid mass had enlarged in a month from the patient's initial visit to the administration of chemotherapy (Figures 4(a) and 4(b)); the tumor showed 


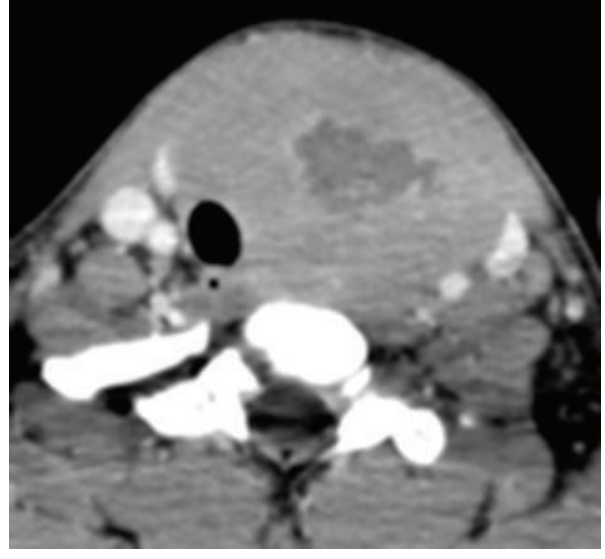

(a)

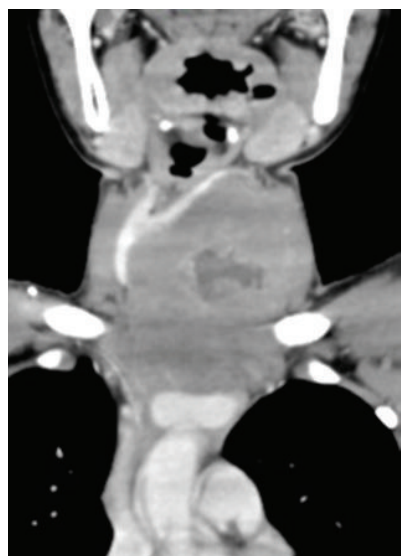

(b)

FIGURE 4: Axial (a) and coronal (b) CT scan showing the thyroid tumor larger than a month before (Figure 2).

rapid response for chemotherapy within 5 days, and a CT scan after the first phase of the treatment revealed a $90 \%$ decrease of the tumor.

A follow-up PET-CT scan after the fourth phase of the treatment showed that the tumor had totally disappeared. The patient has been treated with two years of maintenance chemotherapy consisting of 6-mercaputopurine and methotrexate after four cycles of chemotherapy were administered and has kept recurrence-free survival for 18 months after the beginning of the treatment.

\section{Discussion}

The classification of ML is presented by the 4 th edition of the World Health Organization Classification of Tumors of Haematopoietic and Lymphoid Tissues published in 2008 [12]. In children, Burkitt's lymphoma and T-LBL represent $30-40 \%$, respectively, and both DLBCL and anaplastic large cell lymphoma (ALCL) represent $10 \%$ of all NHLs [13].

Lymphoblastic lymphoma is derived from immature lymphocytes most of which are precursor T-cell origin. TdT is a specialized DNA polymerase expressed in immature lymphoid cells. The clinical distinction between T-LBL and T-ALL is based on the primary site of the disease and the degree of bone marrow involvement. With more than 25\% of bone marrow involvement, the disease is classified as TALL. Because T-LBL is a high-grade lymphoma, CSF as well as bone marrow is involved in a higher rate. Furthermore, mediastinal lymph nodes frequently swell enormously and several complications such as breathing difficulty and superior vena cava syndrome often appear [14].

Before the 1970's a 5-year event-free survival was inferior to $10 \%$; however, now it is well known that ALL-type regimen provides a successful control in T-LBL [15]. Several clinical trials have revealed factors to improve the prognosis of $\mathrm{T}$ LBL, such as application of intensive ALL regimens, long term maintenance therapy, and intensive preventive care of CNS. CFS examination is required at diagnosis, and repeated intrathecal chemotherapy is needed whether malignant cells are revealed or not.
To the best of our knowledge, there have been 8 English literatures reported about pediatric PTL including only one case of a 9-year-old child with T-LBL [2]. Five cases have been in remission after chemotherapy. Because histopathological findings and staging of the disease are necessary for diagnosis and treatment plans, we should carefully perform strategic examinations with the knowledge of this rare malignant disease.

\section{Conflict of Interests}

The authors declare that there is no conflict of interests regarding the publication of this paper.

\section{Acknowledgments}

The authors thank Dr Yuki Yuza and Dr Takashi Kaneko for their valuable suggestions. No funding has been received for the study.

\section{References}

[1] R. K. Marwaha and J. Pritchard, "Primary thyroid lymphoma in childhood: treatment with chemotherapy alone," Pediatric Hematology-Oncology, vol. 7, no. 4, pp. 383-388, 1990.

[2] Y. Hwang, T. Y. Kim, W. B. Kim et al., "Clinical characteristics of primary thyroid lymphoma in Koreans," Endocrine Journal, vol. 56, no. 3, pp. 399-405, 2009.

[3] K. Aozasa, A. Inoue, K. Tajima, A. Miyauchi, F. Matsuzuka, and K. Kuma, "Malignant lymphomas of the thyroid gland: Analysis of 79 patients with emphasis on histologic prognostic factors," Cancer, vol. 58, no. 1, pp. 100-104, 1986.

[4] A. Fiorillo, R. Migliorati, M. Fiore, M. Caldore, G. Menna, and L. Celentano, "Non-Hodgkin's lymphoma in childhood presenting as thyroid enlargement," Clinical Pediatrics, vol. 26, no. 3, pp. 152-154, 1987.

[5] E. C. Weisberger and D. D. Davidson, "Unusual presentations of lymphoma of the head and neck in childhood," The Laryngoscope, vol. 100, no. 4, pp. 337-342, 1990.

[6] A. Aziz Belal, A. Allam, A. Kandil et al., "Primary thyroid lymphoma: a retrospective analysis of prognostic factors and 
treatment outcome for localized intermediate and high grade lymphoma," American Journal of Clinical Oncology: Cancer Clinical Trials, vol. 24, no. 3, pp. 299-305, 2001.

[7] D. Akata, O. Akhan, C. Akyüz, M. N. Özmen, and B. Yalcin, "Involvement of the thyroid and the salivary glands in childhood non-Hodgkin's lymphomas at initial diagnosis," European Journal of Radiology, vol. 44, no. 3, pp. 228-231, 2002.

[8] Y. Iqbal, R. Al-Sudairy, M. F. Abdullah, A. Al-Omari, and S. Crankson, "Non-Hodgkin lymphoma manifesting as thyroid nodules and cardiac involvement," Journal of Pediatric Hematology/Oncology, vol. 25, no. 12, pp. 987-988, 2003.

[9] B. Burkhardt, "Paediatric lymphoblastic T-cell leukaemia and lymphoma: one or two diseases?" British Journal of Haematology, vol. 149, no. 5, pp. 653-668, 2010.

[10] E. Coustan-Smith, J. T. Sandlund, S. L. Perkins et al., "Minimal disseminated disease in childhood T-cell lymphoblastic lymphoma: a report from the Children's Oncology Group," Journal of Clinical Oncology, vol. 27, no. 21, pp. 3533-3539, 2009.

[11] S. B. Murphy, "Classification, staging and end results of treatment of childhood non-Hodgkin's lymphomas: dissimilarities from lymphomas in adults," Seminars in Oncology, vol. 7, no. 3, pp. 332-339, 1980.

[12] S. H. Swerdlow, E. Campo, N. L. Harris et al., WHO Classification of Tumours of Haematopoietic and Lymphoid Tissues, IARC Press, 4th edition, 2008.

[13] N. K. Chadha and V. Forte, "Pediatric head and neck malignancies," Current Opinion in Otolaryngology \& Head and Neck Surgery, vol. 17, no. 6, pp. 471-476, 2009.

[14] D. A. Thomas, S. O’Brien, J. Cortes et al., "Outcome with the hyper-CVAD regimens in lymphoblastic lymphoma," Blood, vol. 104, no. 6, pp. 1624-1630, 2004.

[15] A. Reiter, M. Schrappe, R. Parwaresch et al., "Non-Hodgkin's lymphomas of childhood and adolescence: results of a treatment stratified for biologic subtypes and stage - a report of the Berlin-Frankfurt-Münster group," Journal of Clinical Oncology, vol. 13, no. 2, pp. 359-372, 1995. 


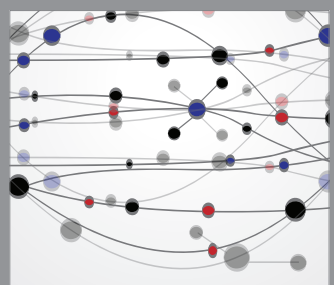

The Scientific World Journal
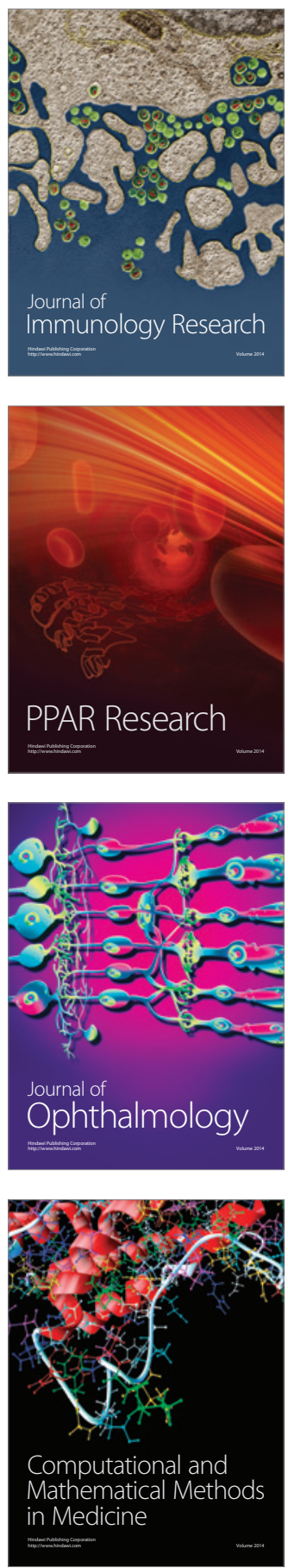

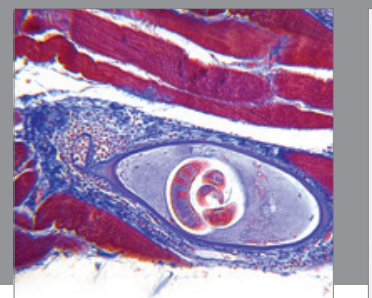

Gastroenterology

Research and Practice
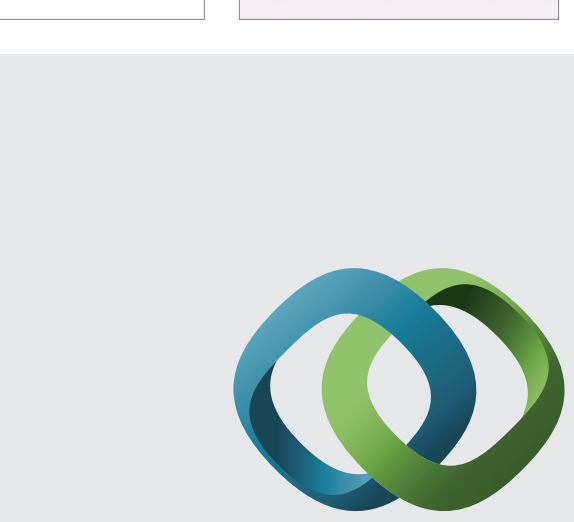

\section{Hindawi}

Submit your manuscripts at

http://www.hindawi.com
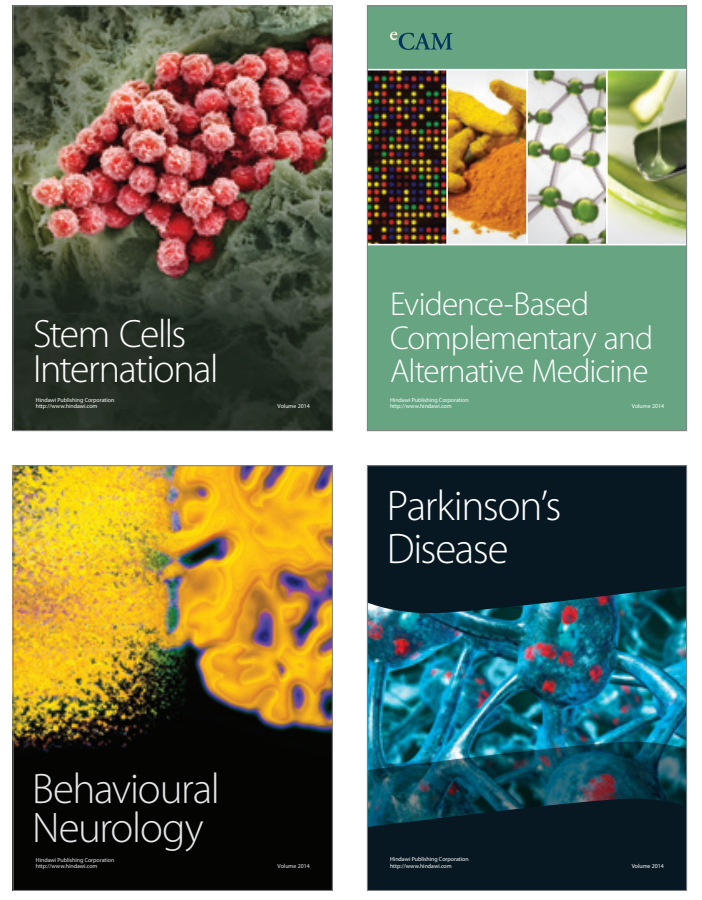
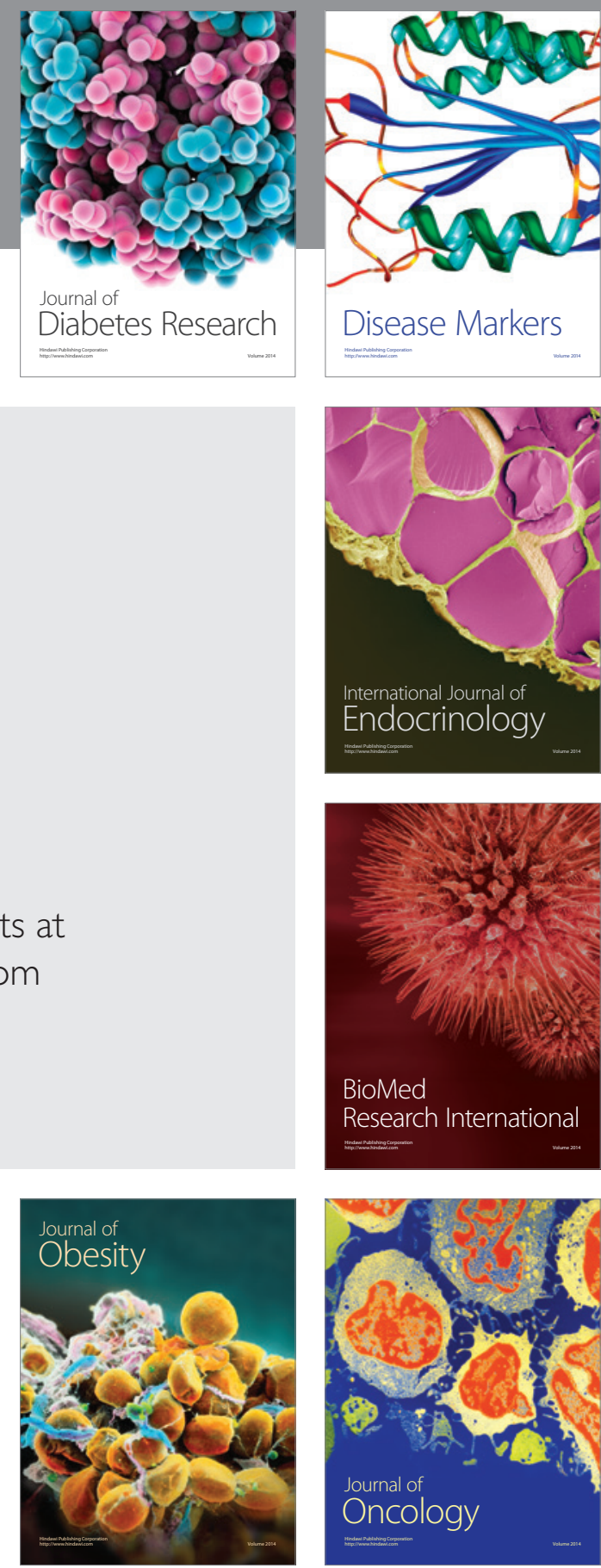

Disease Markers
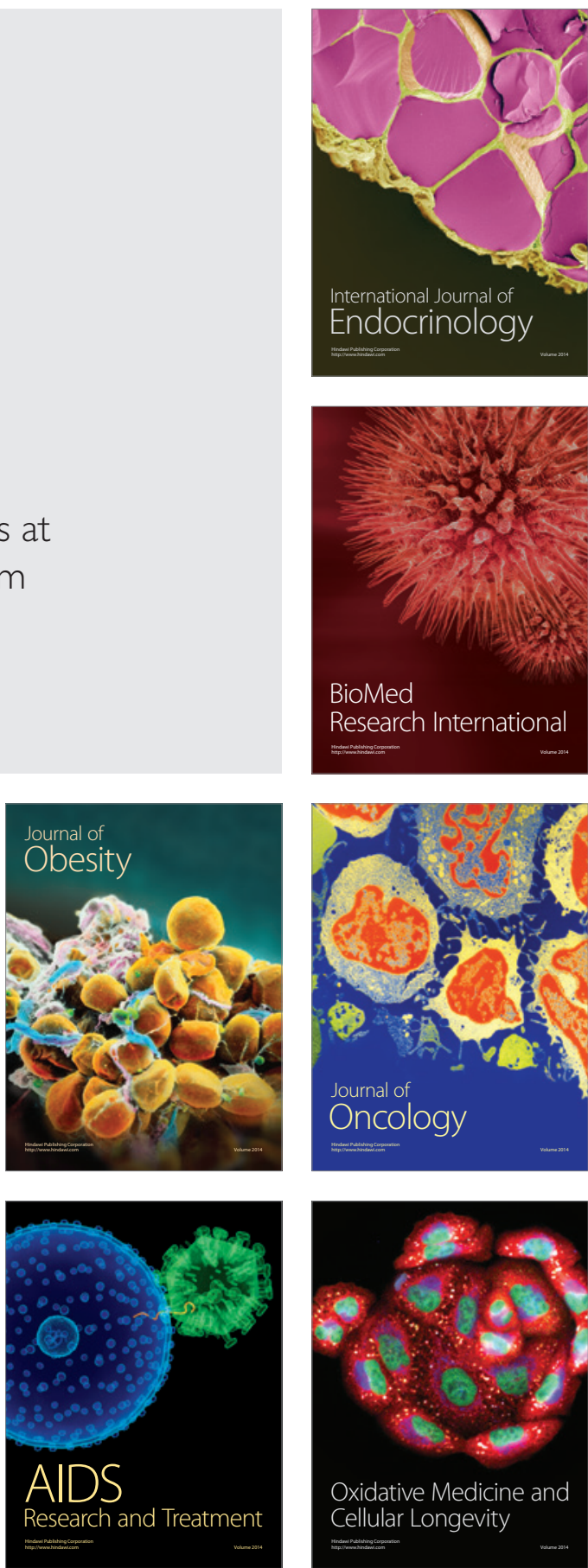